\title{
The role of self-leadership in becoming an ethical leader in the South African work context
}

\author{
EBBEN VAN ZyL
}

\begin{abstract}
Unethical behaviour has reached unacceptable levels in South Africa. Ethical leadership is an important source of ethical influence, and therefore provides an impetus for finding ways of managing ethics in an organisational context. Ethical leadership, however, is influenced and affected by self-leadership. The objective of this conceptual and theoretical research, therefore, was to indicate how self-leadership can contribute to leaders becoming ethical leaders within the current South African work context. The social learning theory can be made applicable to self-leadership and ethical leadership, and was used as the basis for this study. It is indicated that self-leadership strategies can have an effect on ethical behaviour of leaders.
\end{abstract}

Key words: self-leadership, leadership, ethical leadership

\section{INTRODUCTION}

Economies around the world have been severely affected by the global crisis (Dorasamy, 2010). Despite wide-ranging policy responses, intense financial strains and economic slack have not totally disappeared (Dorasamy, 2010). Governments are struggling with ways of managing the emergent economic challenges, while preparing their economies to thrive in a future economic landscape characterised by increasing uncertainty ((World Economic Outlook, 2009:5). While the South African government has responded with strategies to address the effects of the crisis, it can be argued that any response should be underpinned by government's commitment to maintaining ethical leadership.

Within South African businesses, actions are embarked upon with regard to focused and structured attempts at managing ethics (Van Vuuren \& Eiselen, 2006). Within the South African context, the recommendations of the King I Report on Corporate Governance, published in 1994, and, to an even greater extent, the recommendations of the King II report, published in 2002 (Van Vuuren \& Eiselen, 2006), clearly stipulate the institutionalisation and management of ethics as a primary focus of good governance. The King paradigm of corporate governance is built on the premise that governance is not only an ethical imperative, but also that ethics has to be governed, and

Ebben van $\mathbf{Z y l}$ is a professor in the Department of Industrial Psychology at the University of the Free State. He was employed at the University in 1994, and chaired the Department of Industrial Psychology from 1 January 2004 to 1 January 2007.

He has published 41 scientific publications and 42 research projects, and presented 42 papers at national and international conferences on topics related to industrial psychology. 
ethical performance reported on (Van Vuuren \& Eiselen, 2006). Despite the abovementioned actions, unethical behaviour still remains a big problem in the South African business world (Van Zyl, 2012:50).

In the Human Development Report, 2007, South Africa was ranked twenty-first out of 177 countries, and considered a middle-income country (Swedish International Development Cooperation Agency, 2008). In spite of this, there are major differences in income between the rich and the poor, and South Africa is one of the countries in the world where wealth is most unequally distributed (Swedish International Development Cooperation Agency, 2008). About 15 million out of 47.7 million inhabitants are considered very poor, and the unemployment rate is about $30 \%$ (Swedish International Development Cooperation Agency, 2008). High unemployment figures can lead to unethical behaviour and high crime levels (Van Zyl \& Lazenby, 2012). De Koker (2007) is of the opinion that crime (including economic and whitecollar crime) has reached unacceptable levels in South Africa. De Koker (2007) also indicated that fraud and unethical behaviour are a reality in South African public and private companies, and that something should be done to improve the situation.

One way to go about it is for organisations to humanise the way they manage people. This means that leadership has to be proficient, so that subordinates can identify and go along with it, and leaders should serve as role models through their own ethical and moral actions in the workplace (Van Zyl \& Lazenby, 2012). Ethical leadership is an important source of ethical influence, and therefore provides an impetus for finding ways of managing ethics in organisational context (Van Zyl \& Lazenby, 2012). Van Zyl (2001) stated that ethical behaviour by leadership, in particular, can have an important effect on the ethical behaviour of employees. Stead, Worrel, and Stead (1994:110) put it as follows: "The institutionalisation of high ethical standards in corporations stems from the character of persons who occupy the relevant positions. Leaders cannot expect ethical behaviour from employees if they do not behave ethically themselves. Leaders are the most significant role models in the organisational setting; they therefore have a major socialising influence on lower-level employees and ethical behaviour in an organisational context." (Worrel \& Stead, 1994).

Ethical leadership is influenced and affected by self-leadership (Van Sandt \& Neck, 2003). Van Sandt and Neck (2003) are of the opinion that self-leadership through self-influence processes may have an effect on moral actions and ethical leadership in organisations. Under conditions of self-leadership, leaders play a greater role in influencing higher-level management decision making and strategic processes. In terms of a cybernetic control process, leaders are more involved in setting the ethical standard, as well as acting to achieve and maintain the standard once it is set (Van Sandt \& Neck, 2003:376).

The aim of this conceptual and theoretical research therefore, was to indicate how self-leadership can contribute to leaders becoming ethical leaders within the current South African work context.

\section{SELF-LEADERSHIP}

\section{Definitions}

Dion (2012:6) and Neck and Houghton (2006) defined self-leadership as both thoughts (cognition) and actions (behaviour) that people use to influence themselves. It implies that individuals receive their motivation and control from their inner self.

Manz and Neck (1999:589) conceptualised selfleadership as a comprehensive self-influence perspective that concerns leading oneself towards performance of naturally motivating tasks, as well as managing oneself to do work that must be done, but is not naturally motivating.

According to Van Zyl (2012) and Hauschildt and Konradt (2012), when thinking of self-leadership, 
the focus is on self-influencing processes rather than hierarchical control processes. The focus is also on self-observation, self-discovery, and selfdevelopment strategies (Manz \& Simms, 1991). In the self-leadership approach, the modelling of self-leadership behaviour is emphasised, to enable subordinates to also learn the behaviour (Manz \& Neck, 1999).

\section{Origins of self-leadership}

According to Alves, Lovelace, Manz, Matsypura, Toyasaki and Ke (2006), the concept of selfleadership emerged out of the notion of selfmanagement, and relates to the process of influencing oneself. Manz and Neck (1991) provided a comprehensive historical overview of the concept of self-leadership and how it is different from related concepts, including selfregulation and self-management. According to Manz and Neck (1991), self-regulation theory is a descriptive framework to explain how people behave, whereas self-management is a prescriptive framework to suggest how people should behave. However, both these theories do not indicate what types of behaviours should be displayed and why, which is the concern of the self-leadership theory (Ho \& Nesbit, 2013).

Self-leadership is generally portrayed as a broader concept of self-influence that subsumes the behaviour-focused strategies of selfregulation, self-control, and self-management, and then specifies additional sets of cognitiveorientated strategies derived from intrinsic motivation theories (Segon, 2011), social cognitive theories (Bandura, 1986), and positive cognitive psychology (Seligman, 1991). Thus, drawing from these well-established theoretical foundations, self-leadership comprises specific sets of behavioural and cognitive strategies to shape individual outcomes.

Self-leadership strategies are often divided into three basic categories: behaviour-focused strategies, natural reward strategies, and constructive thought patterns (Houghton, Dawley \& DiLiello, 2012; Manz \& Neck, 1999; Manz \& Sims, 1991).
Behaviour-focused strategies involve the self-regulation of behaviour through the use of self-assessment, self-reward, and self-discipline (Manz \& Neck, 1999). These strategies are designed to foster positive, desirable behaviours while discouraging ineffective behaviours. Behaviour-focused strategies are particularly useful in managing behaviour related to the accomplishment of necessary but unpleasant tasks. These strategies include self-observation, self-goal setting, self-reward, self-correcting feedback and practice, management of cues, and proactive networking and teamwork.

Natural reward strategies involve seeking out working activities that are inherently enjoyable (Manz \& Simms, 1991). These strategies also include the focusing of attention on the more pleasant or gratifying aspects of a given job or task, rather than on unpleasant or difficult tasks. Naturally rewarding activities tend to foster feelings of increased competence, selfcontrol, and purpose (Norris, 2008).

\section{Constructive thought pattern strategies} involve the creation and maintenance of functional patterns of habitual thinking (Manz \& Neck, 1999). Specific thought-orientated strategies include the evaluation and challenging of irrational beliefs and assumptions, mental imagery of successful future performance, and positive self-talk.

\section{ETHICAL LEADERSHIP}

\section{Definition}

Zuma (2000:6) defined ethical leadership as leading in a manner that respects the rights and dignity of others. As leaders are by nature in a position of social power, ethical leadership focuses on how leaders use their social power in the decisions they make, the actions they are engaged in, and the ways in which they influence others (Zuma, 2000). Leaders who are ethical demonstrate a level of integrity that is important for stimulating a sense of trustworthiness, which is important in order for followers to accept the vision of the leader. 
Dirks and Ferrin (2002:612) indicated that the character and integrity of the leader provides the basis for personal characteristics that direct a leader's ethical beliefs, values, behaviour, and decisions. Individual values and beliefs impact the ethical decisions and behaviour of leaders (Papa, Daniels \& Spiker, 2008).

Wolmarans (2014) provided a comprehensive definition of ethical behaviour: "Ethical leadership can be defined as the demonstration of normative appropriate conduct through personal actions and interpersonal relationships, and encouraging such conduct through twoway communication with followers. Ethical leadership therefore is not about a process but rather about a way of being and making the right choices (and helping others to make the right choices)."

\section{Origin of ethical leadership}

Attempts at defining ethical behaviour and ethical leadership probably go back to prehistory. Ethical behaviour and leadership are the cornerstones of ancient Greek philosophy and most major world religions (Dirks \& Ferrin, 2002). The word ethics is derived from the Greek word ethos or ethikos, which refers to the character of man, as well as man's ability to distinguish right from wrong (Fox, 2010). Ethical leadership has its origin in ethical behaviour or ethics (Marx \& Els, 2009). Ethical behaviour, in the simplest terms, is knowing and doing what is right. The difficulty lies in defining 'right.' Different individuals, different cultures, and different religions define it in different ways. The accepted treatment of women and attitudes toward slavery in different cultures and at different times in history provide prime examples of how what is 'right' can vary (Fox, 2010).

In older leadership literature, little mention is made of the ethical dimension of leaders (Bass, 1990). However, Yukl (2002) devoted part of a chapter to the topic, suggesting increasing interest in the phenomenon. Previous survey research suggested that traits such as credibility, integrity, honesty, and fairness are associated with perceptions of effective leadership (Bass, 1990; Kouzes \& Possner, 1993). Yukl (2002) also linked ethical leadership with exceptional leadership, such as Burns's concept of transformational leadership (1978).

Marx and Els (2009) and Fox (2010) did more recent work on ethical leadership. According to Marx and Els (2009), ethical leadership has two elements. First, ethical leaders must act and make decisions ethically, as must ethical people in general. Secondly, ethical leaders must also lead ethically - in the ways they treat people in everyday interaction, in their attitudes, in the ways they encourage, and in the directions in which they steer their organisations or institutions or initiatives (Marx \& Els, 2009).

Fox (2010) indicated that ethical leadership is both visible and invisible. The visible part is the way the leader works with and treats others, his behaviour in public, and his statements and actions. The invisible aspects of ethical leadership lie in the leader's character, in his decision-making process, in his mind-set, in the set of values and principles on which he draws, and in his courage to make ethical decisions in tough situations (Fox, 2010).

Some important components of ethical leadership can include:

- The ability to put aside your ego and personal interests for the sake of the cause you support, the organisation you lead, the needs of the people you serve, and the greater good of the community or the world.

- The willingness to encourage and take seriously feedback, opinions different from your own, and challenges to your ideas and proposed actions.

- The encouragement of leadership in others.

- Making the consideration and discussion of ethics and ethical questions and issues part of the culture of the group, organisation, or initiative. 
- Maintaining and expanding the competence that you owe to those who trust you to lead the organisation in the right direction and by the best and most effective methods.

- Accepting responsibility and being accountable.

- Understanding the power of leadership and using it well - sharing it as much as possible, never abusing it, and exercising it only when it will benefit the individuals or the organisation you work with, the community, or society (Fox, 2010).

\section{Towards an integrated self-leadership and ethical leadership theory, utilising the social learning theory}

Bandura (1986) proposed the social learning theory (SLT), which includes three variables, namely behaviour (actions), internal attributes (cognitions and emotions), and environmental factors (within and outside of the organisation).

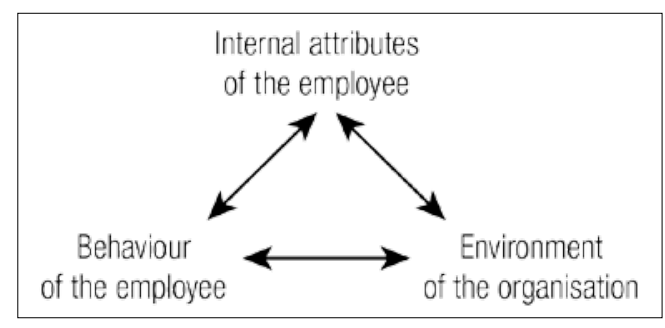

Figure 1: Social learning theory (Van Sandt \& Neck, 2003:374).

These three variables interact reciprocally with each other to explain individual behaviour.

The SLT was extended by Van Sandt and Neck (2003) to ethical behaviour. According to this theory, ethical human behaviour (including leaders' ethical behaviour) can best be explained via a set of continuous, reciprocal interactions among three primary sets of variables: the person, the behaviour of the person, and the environment (Van Sandt \& Neck, 2003:373). According to the SLT, the person, the environment, and the focal behaviour reciprocally interact to explain individual action.

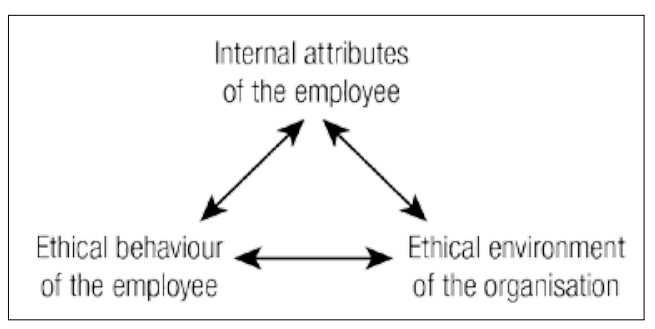

Figure 2: Social learning theory application to leadership ethical behaviour (Van Sandt \& Neck, 2003:374).

Van Sandt and Neck (2003:374) suggested that the ethical behaviour of a leader is influenced by internal aspects (including cognitions and emotions) and the ethical environment (including the existence of ethical codes of conduct and an ethical climate) of the organisation. Internal and external environmental factors can also be reciprocally impacted by ethical behaviour (Van Sandt \& Neck, 2003:374) (see Figure 2).

Van Sandt and Neck (2003) indicated that the SLT of ethical behaviour includes all the critical variables influencing ethical behaviour (i.e. cognitive, emotional, environmental, and behavioural determinants). The authors therefore suggested that effective and ethical leadership behaviour may be grounded in the SLT.

Van Sandt and Neck (2003:375) and Lyons (2001) also stated that other effective leadership behaviours can also be grounded in the SLT. According to them, one such leadership perspective is self-leadership. Although selfleadership behaviour will be affected mostly by the internal attributes of leaders (cognition and emotions), environmental factors (such as the way the environmental climate is empowering the leader to identify and implement selfleadership strategies) will also have an effect on self-leadership behaviour (see Figure 3, where self-leadership and ethical leadership behaviour are integrated in the SLT). 


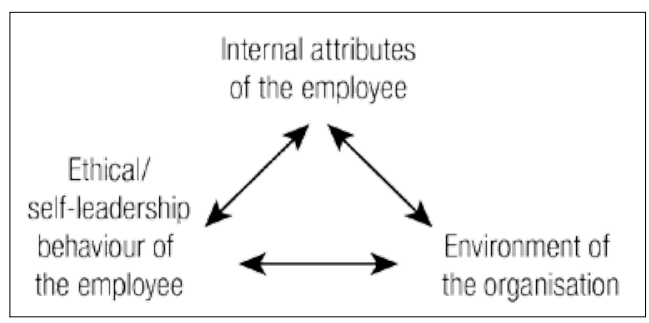

Figure 3: Social learning theory application to ethical leadership/self-leadership behaviour (Van Sandt \& Neck, 2003:374).

The role self-leadership can play in creating ethical leadership within the South African work context, will now be discussed.

\section{THE ROLE SELF-LEADERSHIP}

\section{CAN PLAY IN CREATING ETHICAL} LEADERSHIP WITHIN THE SOUTH AFRICAN WORK CONTEXT

Self-observation (observing one's own actions and thoughts, or getting someone else to do that) and self-assessment (performing a more formal assessment of behaviours and thoughts), according to Van Sandt and Neck (2003:377), involve systematic data gathering about one's own behaviour and cognition. Self-observation and self-assessment are the important first step in the self-leadership process because, it is argued, people cannot influence their own actions if they are inattentive to relevant aspects of their behaviour (Bandura, 1986). According to Rest (1994), moral character in the form of ego strength, perseverance, strength of conviction, and courage are necessary to carry out moral behaviour to its end result. The practices of self-observation and self-assessment can help establish insights regarding the causes of one's behaviour that relate to ethical practices, and provides the basis for change (for instance, if leaders observed unethical thoughts and actions when faced with clients who are willing to pay extra money for preferential treatment, these thoughts and actions, together with the causes for these thoughts and actions, should be identified and rectified).
Another effective behaviour-focused selfleadership strategy involves setting goals for oneself (Alves, Lovelace, Manz, Matsypura, Toyasaki \& Ke, 2006). Research indicates that specific and challenging goals result in improved performance (Van Sandt \& Neck, 2003). Also, the effectiveness of goals can be improved if they are publicly stated, focus on behaviour change, and are short-range instead of distant (Dion, 2012). Self-goal setting with regard to ethical behaviour amongst leaders in the South African work context should therefore be very specific and short-range (for instance: "I am going to think and act according to my own ethical convictions, regardless of difficult ethical circumstances or the lack of specific ethical organisational policies"). Leaders in the South African work context can also inform colleagues of their ethical intentions and ethical actions in difficult situations, which can help to create a climate of ethical thoughts and behaviour in the work place. Regular meetings amongst leaders, where self-goals with regard to ethical behaviour are discussed and encouraged, can help leaders to attain goals.

Self-reward (self-administering positive consequences to increased desired behaviour) and self-correcting feedback and practice (the selfadministration of negative consequences to reduce undesired behaviour) are both forms of consequent modification (Van Sandt \& Neck, 2003; Becker, 2010). Research supports the proposition that self-reinforcement can be effective in self-leadership. Van Sandt and Neck (2003) concluded that self-reinforcement has consistently produced positive outcomes. On the other hand, research evidence has not supported the efficacy of self-punishment as a self-leadership tool (May, Hodges, Chan \& Avolio, 2003). Thus, research suggests that an employee who is working towards an ethicsrelated goal should reward himself/herself (for instance, with a dinner celebration) when improvement is made, but should not dwell on self-criticism if an ethical goal is not achieved in a timely manner (May, Hodges, Chan \& 
Avolio, 2003). Within the South African work situation, leaders should not only create positive consequences for themselves when desired behaviours are attained, but also create positive consequences for colleagues when incidents of desired behaviour are reported (for instance, when a leader has identified and reported unethical conduct in the work situation).

The management of antecedents to behaviour (i.e. cues) encompasses the gradual limiting of discriminative stimuli that evoke undesirable behaviour (for instance, unethical behaviour), while increasing cues for more desirable behaviour (Van Sandt \& Neck, 2003; Kemp, 2002). For the leader in the South African work context seeking to foster continuous personal improvement with regard to ethical behaviour, placing a sign on his/her desk that reads: What is the right thing to do? provides a visual stimulus that cues desired behaviour (e.g., considering the most ethical action to take in difficult ethical situations).

The final behaviour-focused self-leadership strategies are teamwork and proactive networking. Van Sandt and Neck (2003) are of the opinion that employees adept at facilitating proactive teamwork - that is, acting in ways that promote the benefit of others (and not only focusing on acting in ways that benefit themselves) - are the most ethical employees in the workplace. Networking is significantly related to proactive teamwork, but implies a broader stance (Van Sandt \& Neck, 2003; Lange, 2001). Networking implies the employee viewing everyone in the organisation as a teammate and a potential source of help when needed. In support of the abovementioned, the Moral Approbation Model of Jones and Ryan (in Van Sandt \& Neck, 2003), focuses on the fact that people act in ways that tend to gain support and approval from their reference group. In the South African work situation, leaders should focus more on working collectively in solving unethical behaviour, and share concerns/ successes with regard to unethical conduct.
Effective leaders can physically and mentally redesign their tasks to make them more naturally rewarding (Palomino \& Martinez, 2011). This is accomplished by choosing to complete tasks in ways that enable the work to be naturally rewarding. Value is obtained from doing the job itself (pride in workmanship). For example, emphasising ethics and honesty in a leader's job should contribute to a sense of meaning and purpose that extends beyond earning a salary (Van Sandt \& Neck, 2003). Van Sandt and Neck (2003) and Mishra and Sharma (2010) are of the opinion that a sense of meaning and purpose in the job may foster feelings of increased competence, self-control, and purpose. Leaders in the South African work situation may choose to focus on pride in their workmanship or the intrinsic value of their work, which may contribute to the reduction of unethical behaviour.

Constructive thought pattern strategies like utilising rational beliefs, positive self-talk, and mental imagery can contribute to ethical conduct amongst leaders in South Africa. According to Van Sandt and Neck (2003) and Holftreter (2003), rational beliefs can help in situations where dysfunctional thinking is based on some common dysfunctional assumption. For example, consider a leader who is of the opinion that the company's code of conduct does not uphold his/her personal code. $\mathrm{He} /$ she may conclude that there is no way he/ she can work for that company and still adhere to his/her personal code of ethics. An example of a more rational belief is that, although the company's code of conduct seems to exhibit a lower standard his/her own, that doesn't mean that he/she must quit his/her job or act in less ethical ways. This employee should decide to follow his/her own ethical standards while performing to the best of his/her abilities, and this may convince management and colleagues that the organisation can be profitable while exhibiting a higher level of ethical conduct. 
Self-talk can be defined as what we covertly tell ourselves (Van Sandt \& Neck, 2003). Through repeated use, positive or constructive self-talk can become internalised, so that the leader learns to use it automatically and silently at a mental level to constructively enhance his/her own ethical behaviours.

Mental imagery of successful future performance refers to the process of imagining successful performance of a task before it is actually completed (Van Sandt \& Neck, 2003). By applying this within the South African work situation, leaders may focus on how ethics in conduct should be adhered to at all times, which may reduce unethical conduct amongst leaders.

\section{FINAL COMMENTS}

Much attention has been given to the need for more ethical and moral behaviour within South African public and private companies. Despite this, unethical behaviour still remains a big problem in the South African business world. The managerial/leadership hierarchy is an important source of ethical influence and, therefore, if leaders can act in an ethical manner, ethical conduct in South African companies may improve. This means that leadership has to be proficient, so that subordinates can identify and go along with it, i.e. leaders should serve as role models trough their own ethical and moral actions in the workplace.

Ethical conduct amongst leaders in the South African work context can be improved by focusing on certain self-leadership strategies. If South African leaders can be made aware of the advantages of self-leadership and trained in applying it in everyday work situations, unethical conduct in the South African organisational context may be reduced.

\section{REFERENCES}

Alves, J. C., Lovelace, K. J., Manz, C. C., Matsypura, D., Toyasaki, F. \& Ke, K. 2006. A cross-cultural perspective of self-leadership. fournal of Managerial Psychology, 21:338-359.

Bandura, A. 1986. Social foundations of thought and action: A social cognitive theory. Englewood Cliffs: Prentice-Hall.

Bass, B. M. 1990. Bass and Sodgill's handbook of leadership. New York: The Free Press.

Becker, W. S. 2010. Ethics in human resources: An exercise involving new employees. fournal of Human Resources Education, 4(4):27-34.

Boshoff, E. \& Van Zyl, E. S. 2011. The relationship between locus of control and ethical behaviour among employees in the financial sector. Koers, 76(2):20-31.

De Koker, L. 2007. Financial crime in South Africa. Economic Affairs, 27(1):34-38.

Dion, M. 2012. Are ethical theories relevant for ethical leadership? Leadership and Organisation Development fournal, 33:4-24.

Dirks, K. T. \& Ferrin, D. L. 2002. Trust in leadership: Meta-analytic findings and implications for research and practice. Journal of Applied Psychology, 87:611-628.

Dorosamy, N. 2010. The impact of the global crisis on ethical leadership: A case study of the South African public sector. African Journal of Business Management, 4:2087-2096.

Elliot, R. T. 2010. Examining the relationship between personality characteristics and unethical behaviours resulting in economic crime. Ethical Human Psychology and Psychiatry, 12(3):269-276.

Fox, E. 2010. Integrated ethics: An innovative program to improve ethics quality in health care. The Innovation fournal, 15(2):12-24.

Hauschildt, K. \& Konradt, U. 2012. A conceptual framework of self-leadership in teams. Work and Organisational Psychology, 13(1):1-20. 
Holtfreter, K. 2005. Is occupational fraud 'typical' white-collar crime? A comparison of individual and organizational characteristics. Journal of Criminal Fustice, 33:353-365.

Ho, J. \& Nesbit, P. L. 2013. Exploring selfleadership across Eastern and Western cultures. Journal of Service Science and Management, 6:241-249.

Houghton, J. D., Dawley, D. \& Di Liello, T. 2012. The abbreviated Self-Leadership Questionnaire: A more concise measure of self-leadership. International fournal of Leadership Studies, 7(2):216-231.

Hunt, J. G. 1991. Leadership: A new synthesis. Thousad Oaks: Sage.

Kemp, S. 2002. South Africa's dismal corporate ethics. Pretoria: Van Schaik.

Kouzes, J. M. \& Posner, B. Z. 1993. Credibility. San Francisco: Jossey Bass.

Lange, M. 2001. Welcoming remarks. Presented at workshop: The moral renaissance: Government, politics and spirituality, 3-4 May 2000, Johannesburg, South Africa.

Lyons, A. 2011. Leadership ethics and the corporate ethics function: Leveraging $H R$ to mitigate the risk. Capstone Paper, Master of Professional Studies in Human Resource Management. Georgetown: Georgetown University.

Manz, C. C. \& Neck, C. P. 1999. Mastering selfleadership: Empowering yourself for personal excellence. Englewood Cliffs: Prentice Hall.

Manz, C. C. \& Simms, H. P. 1991. Superleadership: Leading others to lead themselves. New York: Berkeley.

Marx, B. \& Els, G. 2009. The role of the audit committee in strengthening business ethics and protecting stakeholders' interests. Africa fournal of Business Management, 4(1):5-15.

May, D. R., Hodges, T. D., Chan, A. Y. L. \& Avolio, B. J. 2003. Developing the moral component of authentic leadership. Organisational Dynamics, 3:247-260.
McGee, J. A. \& Byington, J. R. 2009. The threat of global white-collar crime. Journal of Corporate Accounting \& Finance, 2:25-29.

Mishra, N. \& Sharma, G. 2010. Ethical organisation and employees. Asian Journal of Management Research, 4:59-80.

Neck, C. P. \& Houghton, J. D. 2006. Two decades of self-leadership theory and research. Journal of Managerial Psychology, 21:270-295.

Norris, E. 2008. An examination of selfleadership. Emerging Leadership fourneys, 2:43-61.

Papa, M. J., Daniels, T. D. \& Spiker, B. K. 2008. Organisational communication: Perspectives and trends. Los Angeles: Sage Publications.

Palomino, P. R. \& Martinez, R. 2011. Human resource management and ethical behaviour: Explaining the role of training in the Spanish banking sector. Ramon Llull fournal of Applied Ethics, 2:69-88.

Rest, J. R. 1994. Moral development: Advances in research and theory. New York: Praeger.

Segon, M. 2011. Managing organisational ethics: Professionalism, duty and HR practitioners. Journal of Business Systems, Governance and Ethics, 5(4):13-25.

Seligman, M. E. P. 1991. Learned optimism. New York: Alfred Knopf.

Stead, W. E., Worrell, D. L. \& Stead, G. S. 1994. An integrative model for understanding and managing ethical behaviour in business. In J. Drummond \& B. Bain (Eds.), Managing business ethics, pp. 100-130.

Swedish International Development Cooperation Agency. 2008. Trends in International unemployment. Stockholm: Aarhus.

Van Sandt, C. V. \& Neck, C. P. 2003. Bridging ethics and self-leadership: Overcoming ethical discrepancies between employee and organisational standards. Fournal of Business Ethics, 43:363-387.

Van Vuuren, L. J. \& Eiselen, R. J. 2006. A role for HR in corporate ethics? South African practitioners' perspectives. SA Journal of Human Resource Management, 4(3):22-28. 
Van Zyl, E. S. 2001. Management modelling behaviour: An important requisite for the implementation of business ethics. Koers, 66(3):233-239.

Van Zyl, E. S. 2012. The relation between selfleadership and certain personality traits among a group of first-line supervisors. fournal of Social Sciences, 31(2):159-165.

Van Zyl, E. S. \& Lazenby, K. 2012. The role of leadership in reducing unethical behaviour and white-collar crime in organisational context. Acta Criminologica, 25(2):58-68.

Wolmarans, J. 2014. The effect of core ethical values on ethical leadership, organisational justice, ethical climate and leader effectiveness. Unpublished Master of Commerce thesis. Stellenbosch: Stellenbosch University.
World Economy Outlook. 2009. World economic and financial surveys: Crisis and recovery. Washington: International Monetary Fund.

Yukl, G. 2002. Leadership in organisations. Upper Saddle River: Prentice Hall.

Zuma, J. 2000. The need to restore the moral fibre of our nation. Paper presented at seminar: The moral renaissance - government, politics, ethics and spirituality, 3-4 May 2000, Johannesburg, South Africa. 